\title{
ASO Visual Abstract: Lymph Node Metastases from Visceral Peritoneal Colorectal Metastases are Associated with Systemic Recurrence
}

\author{
Eran Nizri, $\mathrm{MD}, \mathrm{PhD}^{1,2}$ (D), Yaniv Berger, $\mathrm{MD}^{2,3}$, Eraan Green, $\mathrm{MD}^{\mathbf{1}}$, Matan Kyzer, $\mathbf{M D}^{2,3}$, \\ Asaf Aizic, $\mathrm{MD}^{4}$, Nadav Nevo, $\mathrm{MD}^{1}$, Fabian Gerstenhaber, $\mathrm{MD}^{1}$, Joseph M. Klausner, $\mathrm{MD}^{1,2}$, \\ Mordechai Gutman, $\mathrm{MD}^{2,3}$, Guy Lahat, $\mathrm{MD}^{1,2}$, Aviad Hoffman, $\mathrm{MD}^{5}$, and Ravit Geva, $\mathrm{MD}^{2,6}$ \\ ${ }^{1}$ Department of Surgery A, Peritoneal Surface Malignancy and Melanoma Unit, Tel-Aviv Sourasky Medical Center, Tel- \\ Aviv, Israel; ${ }^{2}$ The Sackler Faculty of Medicine, Tel-Aviv University, Tel-Aviv, Israel; ${ }^{3}$ Department of Surgery B, Chaim \\ Sheba Medical Center, Tel Hashomer, Israel; ${ }^{4}$ Institute of Pathology, Tel- Aviv Sourasky Medical Center, Tel-Aviv, Israel; \\ ${ }^{5}$ Department of General Surgery, Rappaport Faculty of Medicine, Technion-Israel Institute of Technology, Haifa, Israel; \\ ${ }^{6}$ Oncology Division, Tel-Aviv Sourasky Medical Center, Tel-Aviv, Israel
}

Visceral peritoneal colorectal metastases may send metastases to lymph nodes of involved organs. These lymphatic metastases are associated with systemic recurrence (http://doi.org/10.1245/s10434-021-10869-3).

Supplementary Information The online version supplementary material available at https://doi.org/10.1245/s10434-021-10966-3.
COMPETING INTERESTS Ravit Geva- Honoraria (Self)BMS, Lilly, Medison, Roche, Novartis, Janssen, Takeda, MSD, Pfizer, MERCK; Advisory/Consultancy-EISAI, Astrazeneca, Bayer, MSD, Novartis, BI. BOL Pharma, Roche; Research Grant/Funding (Institution) -Educational grant to the research unit-Novartis; Travel/Accommodations/Expenses-Merck, Bayer, BMS, Medison; Other; BOL Pharma—options; Pyxis—-Medical lead, options

Publisher's Note Springer Nature remains neutral with regard to jurisdictional claims in published maps and institutional affiliations.

(C) Society of Surgical Oncology 2021

E. Nizri, MD, $\mathrm{PhD}$

e-mail: eran.nizri@mail.huji.ac.il 